ENCYCLOPEDDIE Encyclopédie berbère

BERBERE

1 | 1984

1 | Abadir - Acridophagie

\title{
Note sur la transcription
}

\section{OpenEdition}

\section{Journals}

Édition électronique

URL : http://journals.openedition.org/encyclopedieberbere/762

DOI : 10.4000/encyclopedieberbere.762

ISSN : 2262-7197

Éditeur

Peeters Publishers

\section{Édition imprimée}

Date de publication : 1 novembre 1984

Pagination : 49

ISBN : 2-85744-201-7

ISSN : 1015-7344

Référence électronique

"Note sur la transcription », Encyclopédie berbère [En ligne], 1 | 1984, mis en ligne le 01 septembre 1989, consulté le 05 octobre 2020. URL : http://journals.openedition.org/encyclopedieberbere/762 ; DOI : https://doi.org/10.4000/encyclopedieberbere.762

Ce document a été généré automatiquement le 5 octobre 2020.

(c) Tous droits réservés 


\section{Note sur la transcription}

1 Dans le texte de l'Encyclopédie berbère seuls seront transcrits, en respectant les usages les plus suivis par les linguistes spécialistes du berbère, les noms, berbères et arabes, qui ne sont pas connus habituellement sous une forme française, souvent très discutable certes mais immédiatement reçue par le plus grand nombre des lecteurs; ainsi, on préférera la forme Touareg à Twareg. Il en sera de même pour la plupart des toponymes. On écrira Ghat, Ghadamès, Ghardaïa (et non yat, yadamès, yardaïa), Oran (et non Waran), In Salah (et non Aïn Salah qui est une arabisation récente). On préférera Achakar à Ašakar, tout en donnant cette transcription en tête de la notice, parce que ce site est connu sous cette notation par les préhistoriens; en revanche, Ašir, qui intéresse en premier lieu les orientalistes, sera transcrit ainsi, et non sous la forme « Achir » (qui figurera néanmoins à sa place alphabétique avec renvoi à Ašir). La même règle sera suivie pour les noms de personnes de la période musulmane : on cherchera Abū Tašfin et non Abou Tachfin. Quant à ceux de la période antique on utilisera bien entendu la forme sous laquelle l'Histoire les a retenus mais, dans la mesure du possible, on fera connaître le nom libyque véritable bien que passé par le punique ; ainsi, Micipsa (= MKWSN), Vermina (= Werminad).

2 Cette présentation hétéroclite peut surprendre les linguistes mais l'Encyclopédie berbère est destinée à un très large public qui n'est pas toujours informé des règles de notation phonétique du berbère, celles-ci étant d'ailleurs assez nombreuses. Pour la notation des termes non reçus en français on s'alignera sur le tableau suivant qui respecte les usages les plus suivis dans les études berbères.

\section{INDEX}

Mots-clés : Transcription 